\section{BRAZIULIAN JOURNAL}

OF MEDICAL AND BIOLOGICAL RESFARCH

www.bjournal.com.br
ISSN 0100-879X

Volume 44 (1) 1-83 January 2011

CLINICAL INVESTIGATION

Braz J Med Biol Res, January 2011, Volume 44(1) 53-61

doi: 10.1590/S0100-879X2010007500140

Possible in vivo mechanisms involved in photodynamic therapy using tetrapyrrolic macrocycles

A.G. Filip, S. Clichici, D. Daicoviciu, R.M. Ion, C. Tatomir, L. Rogojan, I. Opris, T. Mocan, D. Olteanu and A. Muresan

The Brazilian Journal of Medical and Biological Research is partially financed by
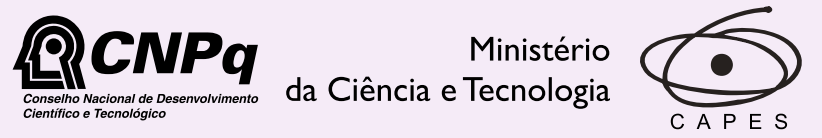

Ministério da Educação

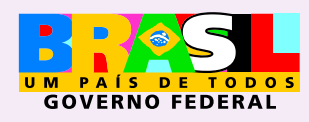

TFAPESP

Institutional Sponsors
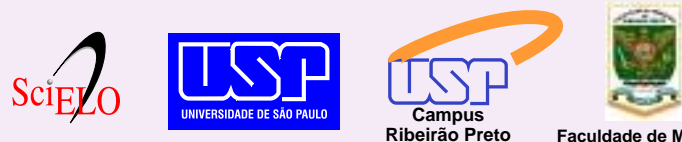

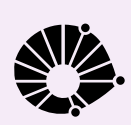

UNICAMP
Ф SHIMADZU

GE Healthcare
Hotsite of proteomics metabolomics developped by: 


\title{
Possible in vivo mechanisms involved in photodynamic therapy using tetrapyrrolic macrocycles
}

\author{
A.G. Filip ${ }^{1}$, S. Clichici ${ }^{1}$, D. Daicoviciu ${ }^{1}$, R.M. Ion², C. Tatomir ${ }^{3}$, \\ L. Rogojan ${ }^{4}$, I. Opris ${ }^{4}$, T. Mocan ${ }^{1}$, D. Olteanu ${ }^{1}$ and A. Muresan ${ }^{1}$ \\ ${ }^{1}$ Department of Physiology, "Iuliu Hatieganu” University of Medicine and Pharmacy, Cluj-Napoca, Romania \\ ${ }^{2}$ National R\&D Institute of Chemistry and Petrochemistry (ICECHIM), Bucharest, Romania \\ ${ }^{3}$ Prof. Dr. I. Chiricuta Oncologic Institute, Cluj-Napoca, Romania \\ ${ }^{4}$ Department of Morphopathology, District Hospital, Cluj Napoca, Romania
}

\begin{abstract}
Photodynamic therapy (PDT) mediated by oxidative stress causes direct tumor cell damage as well as microvascular injury. To improve this treatment new photosensitizers are being synthesized and tested. We evaluated the effects of PDT with 5,10,15,20-tetrakis(4-methoxyphenyl)-porphyrin (TMPP) and its zinc complex (ZnTMPP) on tumor levels of malondialdehyde (MDA), reduced glutathione (GSH) and cytokines, and on the activity of caspase-3 and metalloproteases (MMP-2 and -9) and attempted to correlate them with the histological alterations of tumors in 3-month-old male Wistar rats, $180 \pm 20 \mathrm{~g}$, bearing Walker 256 carcinosarcoma. Rats were randomly divided into five groups: group 1, ZnTMPP+irradiation (IR) $10 \mathrm{mg} / \mathrm{kg}$ body weight; group 2, TMPP+IR 10 mg/kg body weight; group 3, 5-aminolevulinic acid (5-ALA+IR) $250 \mathrm{mg} / \mathrm{kg}$ body weight; group 4, control, no treatment; group 5, only IR. The tumors were irradiated for 15 min with red light $\left(100 \mathrm{~J} / \mathrm{cm}^{2}, 10 \mathrm{kHz}, 685 \mathrm{~nm}\right) 24 \mathrm{~h}$ after drug administration. Tumor tissue levels of MDA (1.1 \pm 0.7 in ZnTMPP vs $0.1 \pm 0.04 \mathrm{nmol} / \mathrm{mg}$ protein in control) and TNF- $\alpha$ (43.5 \pm 31.2 in ZnTMPP vs $17.3 \pm 1.2 \mathrm{pg} / \mathrm{mg}$ protein in control) were significantly higher in treated tumors than in controls. Higher caspase- 3 activity $(1.9 \pm 0.9$ in TMPP vs $1.1 \pm 0.6 \mathrm{OD} / \mathrm{mg}$ protein in control) as well as the activation of MMP-2 $(\mathrm{P}<0.05)$ were also observed in tumors. These parameters were correlated (Spearman correlation, $P<0.05$ ) with the histological alterations. These results suggest that PDT activates the innate immune system and that the effects of PDT with TMPP and ZnTMPP are mediated by reactive oxygen species, which induce cell membrane damage and apoptosis.
\end{abstract}

Key words: Photodynamic therapy; Oxidative stress; Apoptosis; Tetrapyrrolic macrocycles; Cytokines

\section{Introduction}

Photodynamic therapy (PDT) represents a new approach to the treatment of neoplastic and non-neoplastic diseases involving the activation of a photosensitive substance with preferential uptake in the targeted tissue and activated by light. In the presence of oxygen, the activated photosensitizer (PS) generates singlet oxygen by an energy transfer mechanism (type II reaction) and other reactive oxygen species (ROS) including hydrogen peroxide, superoxide anion and hydroxyl radicals by interaction with biomolecules (type I reaction) (1).

The probable targets of PDT are mitochondria, lysosomes, plasma membrane, nucleus of tumor cells, and blood vessels (2). Actually, the results of the in vivo use of PDT depend on the effect this therapy has on the tumor cells, on the vascular endothelial cells, and on the immune cells of the host. Combining these effects may lead to long-term control of the tumor (3).

Cell death following the application of PDT is either due to necrosis or apoptosis depending on the experimental model, the type or dose of PS, and the energy and wavelength of the light $(3,4)$. Apoptosis is the dominant form of cell death in PDT because most of the PS accumulates in the mitochondrial membrane (5). The apoptotic process may be triggered by mitochondrial-dependent mechanisms or by the receptors in the plasma membrane using the intracellular signaling pathways involving calcium ions, ceramides, c-AMP, protein kinases, transcription factors, lipid peroxides, etc. (1). Caspase-3 is the major effector in these pathways,

Correspondence: A.G. Filip, Department of Physiology, "Iuliu Hatieganu" University of Medicine and Pharmacy, 400605 Cluj-Napoca, Romania. Fax: +40-264-59-7257. E-mail: adrianafilip33@yahoo.com

Received July 1, 2010. Accepted November 19, 2010. Available online December 3, 2010. Published January 17, 2011. 
being responsible for the cleavage of the other caspases (-6, $-7,-8)$ and finally for the cleavage of some nuclear proteins involved in DNA repair $(3,6)$.

In addition to having a direct cytotoxic effect, PDT may initiate an immune response against the remaining tumor cells. This process involves macrophages and/or the dendritic cells from the tumor, pro-inflammatory cytokines, chemokines (interleukin-1ß (IL-1ß), tumor necrosis factor-alpha (TNF- $\alpha$ ), IL-6, inflammatory proteins from the macrophage (MIP-1, MIP-2), and adhesion molecules (2,7). The pro-inflammatory cytokines and ROS activate the matrix metalloproteases (MMPs), which are proteolytic enzymes involved in the degradation of the extracellular matrix and also in invasion, angiogenesis, and metastasis $(8,9)$.

A major objective of PDT is to find an ideal PS with maximum efficiency and minimum side effects. This substance has to be chemically homogenous, with a preferential uptake in the tumor, with a rapid clearance and absorption peak at greater than $630-n m$ wavelength, and must generate large amounts of singlet oxygen and be non-toxic. The 5,10,15,20-tetrakis(4-methoxyphenyl)-porphyrin (TMPP) and $\mathrm{Zn}$ (II) TMPP (ZnTMPP) seem to have the qualities of an ideal PS.

TMPP is a tetrapyrrolic macrocycle with a high absorption coefficient in the visible spectrum and with a long life of the triplet state. The methoxy substituents give this compound important photophysical and photosensitizing properties, increasing its polarity but at the same time conserving the lipophilic character conferred by the tetraphenyl-porphyrin, thus insuring a good interaction with the tissue. The complex with metals such as Zn (II) and Cd (II) increases the compound's life in the triplet state and the quantity of singlet oxygen produced, leading to an amplified photodynamic effect (10). Studies performed on TMPP have shown that these photosensitizers can be used as model compounds to investigate the theoretical and instrumental aspects of PDT (11).

The present study was designed to evaluate the mechanism involved in PDT with TMPP and ZnTMPP in an experimental model using the Walker tumor. We studied the effects of PDT on lipid peroxidation and the release of inflammatory cytokines, on the activation of MMPs and on the triggering of apoptosis in correlation with the histopathological findings in the tumor. Also, we measured the level of glutathione in tumor tissue, glutathione being a non-enzymatic antioxidant and a key regulator in the expression of genes involved in apoptosis and inflammation. The effects of PDT with ZnTMPP and TMPP were compared to those obtained using delta aminolevulinic acid (5-ALA), a substance that is being currently used in the PDT of skin cancers and oral cavity dysplasias.

\section{Material and Methods}

\section{Reagents}

TMPP and ZnTMPP were obtained from R.M. Ion,
ICECHIM, Bucharest, Romania. The synthesis was done by adapting literature data, as follows: anisaldehyde (6.05 $\mathrm{mL}, 0.05 \mathrm{~mol}$ ) was warmed to reflux in a mixture of 150 $\mathrm{mL}$ propionic acid and $6.6 \mathrm{~mL}$ propionic anhydride. Pyrrole (3.55 mL, 0.05 mol; Sigma-Aldrich Inc., Germany) was added dropwise to the boiling mixture with vigorous stirring and reflux maintained for 30 to 40 min. Next, 75 $\mathrm{mL}$ ethylic ether (Chimopar, Romania) was added to the warm mixture to induce rapid crystallization. The porphyrin crystallized as violet crystals. The resulting crystals were washed with warm water and then with a small portion of ethylic ether (24\% yield) (12-19). To form the zinc complex of this porphyrin, $0.1 \mathrm{mg}$ TMPP was refluxed in $35 \mathrm{~mL}$ dimethylformamide (DMF; Sigma-Aldrich Inc.) for $1 \mathrm{~h}$. After the porphyrin dissolved completely, $1 \mathrm{~g} \mathrm{ZnCl}_{2}$ (Chimopar) was added and reflux was continued for $2 \mathrm{~h}$. The reaction mixture was concentrated using DMF distillation (b.p. = $153^{\circ} \mathrm{C}$ ) and dilution with distilled water was then performed. The precipitate was filtered and washed with distilled water. The material was dried in an exsiccator over $\mathrm{CaCl}_{2}$ (Chimopar) and $\mathrm{KOH}$ (Chimopar). Red crystals were separated after refluxing and filtration (12).

TMPP was characterized by the following spectral techniques: UV-Vis (dichloromethane) - $\lambda_{\max }(\lambda)(\varepsilon)\left(\mathrm{M}^{-1}\right.$. $\left.\mathrm{cm}^{-1}\right)$ : 420 (28.11 x 104); $518.71\left(11.4 \times 10^{3}\right) ; 555$ (7.75 x $\left.10^{3}\right) ; 593\left(3.925 \times 10^{3}\right) ; 650.13\left(4.122 \times 10^{3}\right)$. FT-IR ( $\left.\mathrm{KBr}\right)$, $\mathrm{cm}^{-1}$ : 752 (Y.C-H Ph), 801 (Y.C-H Pyrrol), 1032 (V.C-O-C), 1096 and 1176 (ס.C-H Pyrrol), 1248 (V.C-O-C), 1352 (V.C-N), 1464 $(\mathrm{v} \cdot \mathrm{C}=\mathrm{N}), 1488(\mathrm{v} \cdot \mathrm{C}=\mathrm{C}$ Pyrrol $), 1512(\mathrm{~V} \cdot \mathrm{C}=\mathrm{C}$ Ph$), 1544$ and 1608 (v.C=C Pyrrol), 3424 (v.N-H).

$\mathrm{Zn}$-TTMP was characterized using the following spectral techniques: UV-Vis (dichloromethane) - $\lambda_{\max }(\lambda)(\varepsilon)\left(\mathrm{M}^{-1}\right.$. $\left.\mathrm{cm}^{-1}\right)$ : 422.71 (5.7); 597.62 (4.23); 672.13 (4.32). FT-IR $(\mathrm{KBr}), \mathrm{cm}^{-1}: 698$ (VZn-N), 767 (Y.C-H Ph), 849 (Y.C-H Pyrrol), 993, 1004 and 1055 (V.C-O-C), 1064 and 1171 (ठ.C-H Pyrrol), 1223 (v.C-O-C), 1306 (v.C-N), 1441 (v.C=N), 1481 (v.C=C Pyrrol), $1520(\mathrm{v} \cdot \mathrm{C}=\mathrm{C} \mathrm{Ph}), 1552$ and $1592(\mathrm{v} \cdot \mathrm{C}=\mathrm{C}$ Pyrrol).

5-ALA (98\%) was obtained from Sigma-Aldrich Inc. Absolute ethanol and n-butanol were purchased from Chimopar. Sodium dodecyl sulfate (SDS), $\mathrm{KH}_{2} \mathrm{PO}_{4}$, 2-thiobarbituric acid, acetonitrile, dithiobisnitrobenzoic acid, Tris, Triton X-100, o-phtalaldehyde, and trichloracetic acid were purchased from Sigma-Aldrich Inc. and EDTA-Na was obtained from Merck KGaA Damstadt (Germany). All reagents were of analytical grade. Caspase-3 and TNF- $\alpha$ kits were purchased from R\&D Systems (USA).

\section{Animals and tumor}

The study was performed on 50 Walker carcinosarcoma 256-bearing male Wistar rats ( $180 \pm 20 \mathrm{~g}, 3$ months old). The animals were randomly divided into 5 groups of 10 animals each: group 1 (ZnTMPP+IR) received ZnTMPP, $10 \mathrm{mg} / \mathrm{kg}$ body weight, intraperitoneally (ip), and was irradiated; group 2 (TMPP+IR) received TMPP, $10 \mathrm{mg} / \mathrm{kg}$ body weight, ip, and was irradiated; group $3(5-A L A+I R)$ received 5-ALA, 
$250 \mathrm{mg} / \mathrm{kg}$ body weight, ip, and was irradiated; group 4 (control) no treatment; group 5 (IR), the tumors were only irradiated. Albino Wistar rats were obtained from the Animal Department of "Iuliu Hatieganu" University of Medicine and Pharmacy, Cluj-Napoca, Romania. They were kept for 10 days on a 12-h dark/12-h light cycle in the Physiology Department in order to acclimate them. The animals were fed a standard pellet diet and received water, both ad libitum. All experiments were performed according to the approved animal care protocols of the Ethics Committee on Animal Welfare of the "Iuliu Hatieganu" University in accordance with the Romanian Ministry of Health and complying with the Guiding Principles for the Use of Animals in Toxicology (20). The rats were grafted subcutaneously (sc) with small fragments of Walker tumor in the right thigh and PDT was applied when the tumor reached $1 \mathrm{~cm}^{3}$.

\section{PDT protocol}

Drug administration. TMPP and ZnTMPP were dissolved in $0.5 \mathrm{~mL}$ dimethyl sulfoxide (DMSO) and injected ip, 10 $\mathrm{mg} / \mathrm{kg}$ body weight. 5-ALA chlorhydrate was dissolved in PBS. The solution was brought to $\mathrm{pH} 7$ with $1 \mathrm{~N} \mathrm{NaOH}$. Each animal received a 5-ALA dose of $250 \mathrm{mg} / \mathrm{kg}$ body weight, ip. All solutions were protected from light with aluminum sheets.

Light treatment. Light treatment was applied $24 \mathrm{~h}$ after drug administration. The animals were shaved on the right thigh and anesthetized with a ketamine xylazine cocktail (90 mg/kg ketamine, $10 \mathrm{mg} / \mathrm{kg}$ xylazine) injected ip. Irradiation was performed with red light applied directly to the skin above the tumor $(\lambda=685 \mathrm{~nm})$ at a dose of $100 \mathrm{~J} / \mathrm{cm}^{2}$, at a mean power of $25 \mathrm{~W}$ and a frequency of $10 \mathrm{kHz}$, for $15 \mathrm{~min}$. The light source was a Therapeutic Laser model D-68 (MARP Electronic, Poland). The rats were killed by cervical dislocation $24 \mathrm{~h}$ after irradiation and the tumors were removed, fragmented, frozen, and kept at $-80^{\circ} \mathrm{C}$. All parameters were determined on a tumor homogenate. For histopathological examination, two tumors from each group were immersed and fixed in $4 \%$ formalin solution.

\section{Oxidative stress parameters}

Malondialdehyde (MDA). MDA, the marker most frequently used for lipid peroxidation, was determined by the fluorimetric method with 2-thiobarbituric acid (TBA) described by Conti et al. (21). The protein content of the homogenates was determined by the method of Bradford (22) using bovine serum albumin as the standard. The homogenates of skin were heated in a boiling water bath for $1 \mathrm{~h}$ in $75 \mathrm{mM} \mathrm{K}_{2} \mathrm{HPO}_{4}, \mathrm{pH} 3$, containing $10 \mathrm{mM}$ TBA. After cooling, the solution was extracted with $3 \mathrm{~mL} n$-butanol in $0.6 \mathrm{~mL}$ TBA. MDA was determined spectrofluorimetrically in the organic phase using a synchronous technique with excitation at $534 \mathrm{~nm}$ and emission at $548 \mathrm{~nm}$. MDA is reported as $\mathrm{nmol} / \mathrm{mg}$ protein.

Reduced glutathione (GSH). GSH was measured fluorimetrically using o-phthalaldehyde and is reported as $\mathrm{nmol} / \mathrm{mg}$ protein (23). The protein pool from the tumor homogenate was precipitated with $10 \%$ trichloroacetic acid and centrifuged. A 0.1-mL solution of o-phthalaldehyde (1 $\mathrm{mg} / \mathrm{mL}$ in methanol) was added to the supernatants diluted with $0.1 \mathrm{M}$ sodium phosphate buffer containing $5 \mathrm{mM}$ EDTA, $\mathrm{pH} 8.0$, and fluorescence was measured after $15 \mathrm{~min}$ (350 $\mathrm{nm}$ excitation and $420 \mathrm{~nm}$ emission).

\section{Caspase-3}

Caspase-3 activity was determined using a colorimetric assay according to manufacturer instructions and was estimated as optical density units (OD)/mg protein (R\&D Systems, GmbH, Germany).

\section{Determination of MMP activity}

The activity of gelatinases was determined by zymography (24). Skin samples were homogenized with an Ultra Turrax homogenizer in a medium with $2 \%$ glycerin and $2 \%$ SDS in $62.5 \mathrm{mM}$ Tris- $\mathrm{HCl}$ buffer. After centrifugation at $12,000 \mathrm{~g}$, the protein in the supernatant was determined by a modification of Lowry's method (25). Five-microgram protein samples were subjected to electrophoresis on $10 \%$ polyacrylamide gels copolymerized with $1 \mathrm{~g} / \mathrm{mL}$ gelatin at $100 \mathrm{~V}$ for $2 \mathrm{~h}$. After electrophoresis, the gels were washed with $2.5 \%$ Triton $\mathrm{X}-100$ for $1 \mathrm{~h}$, then incubated for $18 \mathrm{~h}$ at

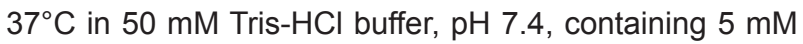
$\mathrm{CaCl}_{2}, 200 \mathrm{mM} \mathrm{NaCl}$ and $0.02 \%$ BRIJ-35. Then, the gels were stained with $1 \%$ Coomassie brilliant blue R-250 for $2 \mathrm{~h}$ and discolored in 10\% acetic acid. The proteolytic activity appeared as clear lytic white bands on an otherwise blue gel. Activity was determined with an automated Vilber-Lourmet (France) image analyzer using the Bio 1-D program. Proteolytic activity was determined against a weight marker, confirmed with an enzymatic marker and

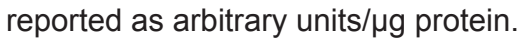

\section{TNF- $\alpha$}

TNF- $\alpha$ levels were assessed by ELISA according to manufacturer instructions (R\&D Systems, $\mathrm{GmbH}$ ).

\section{Histological examination}

Tumor fragments, $10 / 10 / 10 \mathrm{~mm}$ in diameter, were harvested $24 \mathrm{~h}$ after treatment and fixed in $4 \%$ formalin for histopathological examination. The sections were embedded in paraffin, stained with hematoxylin-eosin and examined with a Nikon YS2-H microscope. The Weibel scale was used to dimension the microscopic field (26). Each field had an area of $0.156 \mathrm{~mm}^{2}$. Necrosis was assessed by counting viable and necrotic cells in each microscopic field. The percentage of necrotic cells within the total number of cells on 10 randomly chosen microscopic fields was calculated. Also, the percentage of necrotic cells per $\mathrm{mm}^{2}$ was determined at 400X magnification. Both of these quantitative estimates were carried out in a double-blind manner. 


\section{Statistical analysis}

Data are reported as means \pm SD and were analyzed by non-parametric methods, i.e., the Kruskal-Wallis to assess the variance among all groups and the Mann-Whitney U-test to compare two groups separately (TMPP+IR or ZnTMPP+IR vs 5-ALA+IR, control, and IR groups). The correlations between different parameters were assessed by calculating the Spearman $r$ coefficient. The level of significance was set at $P<0.05$. The statistical packages SPSS 13.0 (SPSS Inc., USA) and MedCalc 8.1.0.0 were used for data analysis.

\section{Results}

The groups that received PDT treatment with TMPP and ZnTMPP were compared to the groups that received 5-ALA and also to control and IR groups, one receiving no treatment and the other only exposed to light without receiving $P S$.

\section{Malondialdehyde}

MDA is a marker that shows the effect of ROS on lipids. The MDA levels in tumor homogenates from the group receiving PDT with $\mathrm{ZnTMPP}(1.1 \pm 0.7 \mathrm{nmol} / \mathrm{mg}$ protein) and the group receiving PDT with TMPP $(0.7 \pm 0.2 \mathrm{nmol} /$ $\mathrm{mg}$ protein) were increased compared to the control group $(0.1 \pm 0.04 \mathrm{nmol} / \mathrm{mg}$ protein $)$ or IR group $(0.1 \pm 0.08 \mathrm{nmol} /$ $\mathrm{mg}$ protein; $\mathrm{P}=0.009)$. PDT with $5-\mathrm{ALA}(0.7 \pm 0.2 \mathrm{nmol} /$ $\mathrm{mg}$ protein) induced lipid peroxidation $(P<0.009 \mathrm{vs}$ control group) in the tumor but MDA values did not differ significantly from those of the groups treated with ZnTMPP and TMPP PDT ( $P$ > 0.05; Figure 1). The Kruskal-Wallis test showed a statistically significant difference in MDA levels between all groups $(P=0.0001)$. When comparing the MDA values between the group that underwent PDT with TMPP and the one treated with ZnTMPP, we found no significant difference between the two groups.

\section{Reduced glutathione}

PDT with $10 \mathrm{mg} / \mathrm{kg}$ body weight ZnTMPP resulted in a 17.0-fold increase in tumor GSH levels compared to control, untreated tumors $(17.3 \pm 1.3$ vs $1.0 \pm 0.1 \mathrm{nmol} / \mathrm{mg}$ protein; $\mathrm{P}<0.014)$. When PDT was performed with TMPP, GSH was significantly higher compared to the IR group (15.0 \pm 2.7 vs $1.4 \pm 0.3 \mathrm{nmol} / \mathrm{mg}$ protein; $\mathrm{P}<0.014)$. PDT with $5-\mathrm{ALA}$ resulted in moderately higher (5.22-fold) levels of GSH compared to control $(P<0.025)$. Treatment with the new porphyrins induced the highest level of GSH compared to the group treated with 5-ALA PDT ( $P=0.034$; Figure 1).

\section{Caspase-3 activity}

As shown in Figure 2, the caspase-3 activity was two times higher in tumors from animals receiving 5-ALA PDT compared to control, untreated animals $(2.6 \pm 0.8$ vs $1.1 \pm$ $0.6 \mathrm{OD} / \mathrm{mg}$ protein; $\mathrm{P}=0.03)$. TMPP PDT induced the acti- vation of the enzyme but at lower levels, with a statistically significant difference for the group treated with 5-ALA ( $P$ $=0.02)$. ZnTMPP PDT did not increase caspase- 3 activity compared to the control and IR groups $(P>0.05)$. In the latter group, caspase-3 activity was lower compared to the group treated with 5-ALA ( $P=0.033$; Figure 2). The Kruskal-Wallis test used to evaluate the global differences between groups showed $P=0.038$. Caspase- 3 activity was correlated directly with glutathione level only for the group treated with 5-ALA PDT $(r=0.8 ; P<0.05)$.

\section{MMP-2 activity}

MMPs are endopeptidases involved in tumor growth, angiogenesis, invasion, and metastasis. Analysis of zymographic images revealed the presence of MMP-2 (proen-
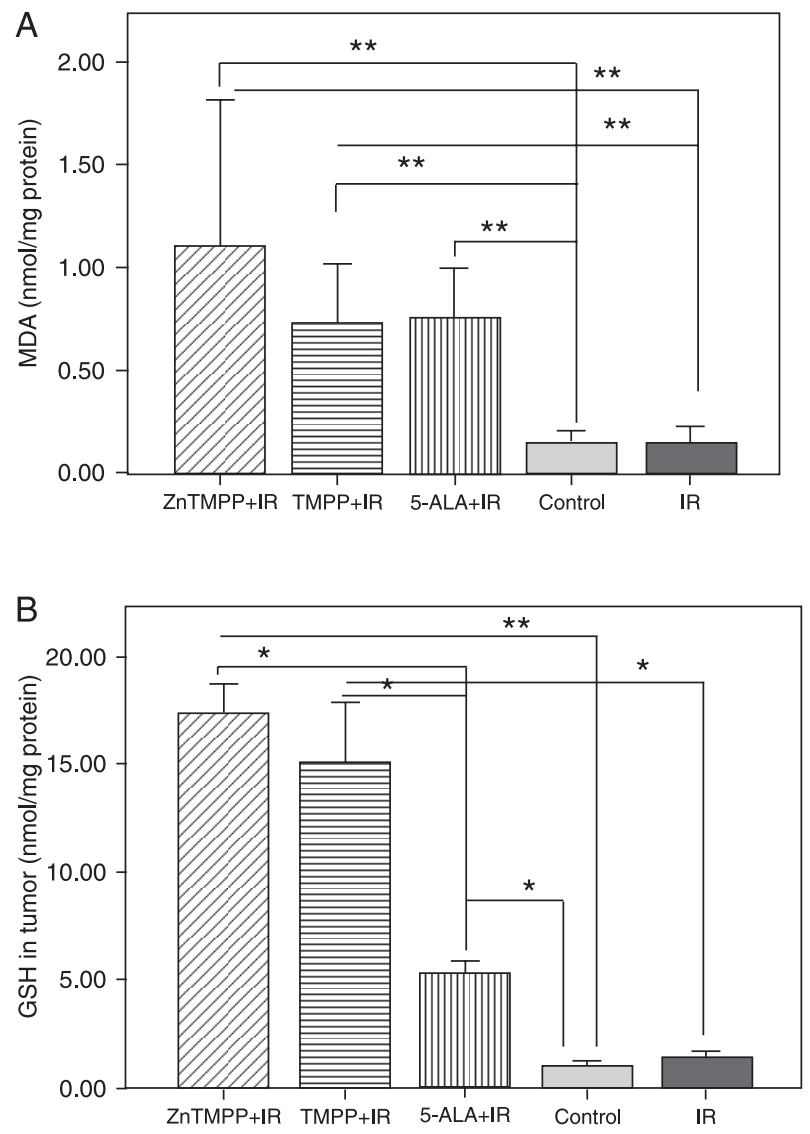

Figure 1. Parameters of oxidative stress (MDA) and antioxidant defense (GSH) in tumor tissue of Walker carcinosarcomabearing rats $24 \mathrm{~h}$ after photodynamic therapy with ZnTMPP, TMPP and 5-ALA. Data are reported as means \pm SD of three independent experiments. MDA $=$ malondialdehyde; $\mathrm{TMPP}=$ 5,10,15,20-tetrakis(4-methoxyphenyl)-porphyrin; ZnTMPP = TMPP zinc compound; 5-ALA = 5-aminolevulinic acid; GSH = reduced glutathione; IR = irradiation. Statistical analysis was done using the Mann-Whitney U-test and the Kruskal-Wallis test. A, MDA: ${ }^{* *} \mathrm{P}<0.01$. B, GSH: ${ }^{*} \mathrm{P}<0.05 ;{ }^{* *} \mathrm{P}<0.01$. 
zyme and mature forms) in all groups studied. The activity of MMP-9 could not be quantified zymographically. The activity of proMMP-2 revealed by zymographic bands was significantly increased in PDT with ZnTMPP compared to the control group $(P=0.03$; Figure 2$)$. Also, the enzymatic activity of MMP-2 was amplified after PDT with ZnTMPP compared to the control group $(P=0.05)$ and also compared to the group treated with $5-A L A(P=0.05)$. ProMMP-2 activity was indirectly correlated $(r=-1 ; P=0.01)$ with the MDA levels when the tumors were treated with 5-ALA PDT.

\section{TNF- $\alpha$}

PDT with ZnTMPP, TMPP and 5-ALAinduced the release of cytokines from tumor cells. The tumor levels of TNF- $\alpha$ when PDT with ZnTMPP was used $(43.5 \pm 31.2 \mathrm{pg} / \mathrm{mg}$ protein) were higher compared to those of tumors treated with TMPP (19.7 $\pm 6.2 \mathrm{pg} / \mathrm{mg}$ protein; $\mathrm{P}=0.03$; Figure 3$)$. 5-ALA PDT induced increased TNF- $\alpha$ levels in tumor tissue (37.7 $\pm 3.2 \mathrm{pg} / \mathrm{mg}$ protein) compared to the control and IR groups $(17.3 \pm 1.2$ and $16.4 \pm 3.0 \mathrm{pg} / \mathrm{mg}$ protein, respectively) or the group treated with TMPP $(P=0.05)$.

\section{Histological studies}

The tumor specimens stained with hematoxylin-eosin (HE) were examined under a Nikon YS2-H microscope in order to detect the onset of intra-tumor necrosis. Twenty-four hours after ZnTMPP, TMPP and 5-ALA PDT, amorphous cells with pyknotic or absent nuclei, without clear intercellular limits and interspersed with viable cell areas were observed. The treatment led to edema, vascular congestion and profuse leukocytic inflammatory infiltration in the intratumor septs especially in the group treated with 5-ALA. In some areas, necrosis was greatly extended, predominantly in the center of the tumor, and the architecture was altered (Figure 4). The following results were obtained when necrotic cells on 10 randomly chosen microscopic fields (400X) or per $\mathrm{mm}^{2}$, were determined, respectively, ZnTMPP+IR: 19.4 $\pm 2.1 \%$; TMPP+IR: $30.0 \pm 3.0 \% ; 5-A L A+I R: 32.4 \pm 0.6 \%$; control: $20.7 \pm 0.8$; IR: $21.1 \pm 1.6$ (Figure 4). The magnification of the histological images was 40X.
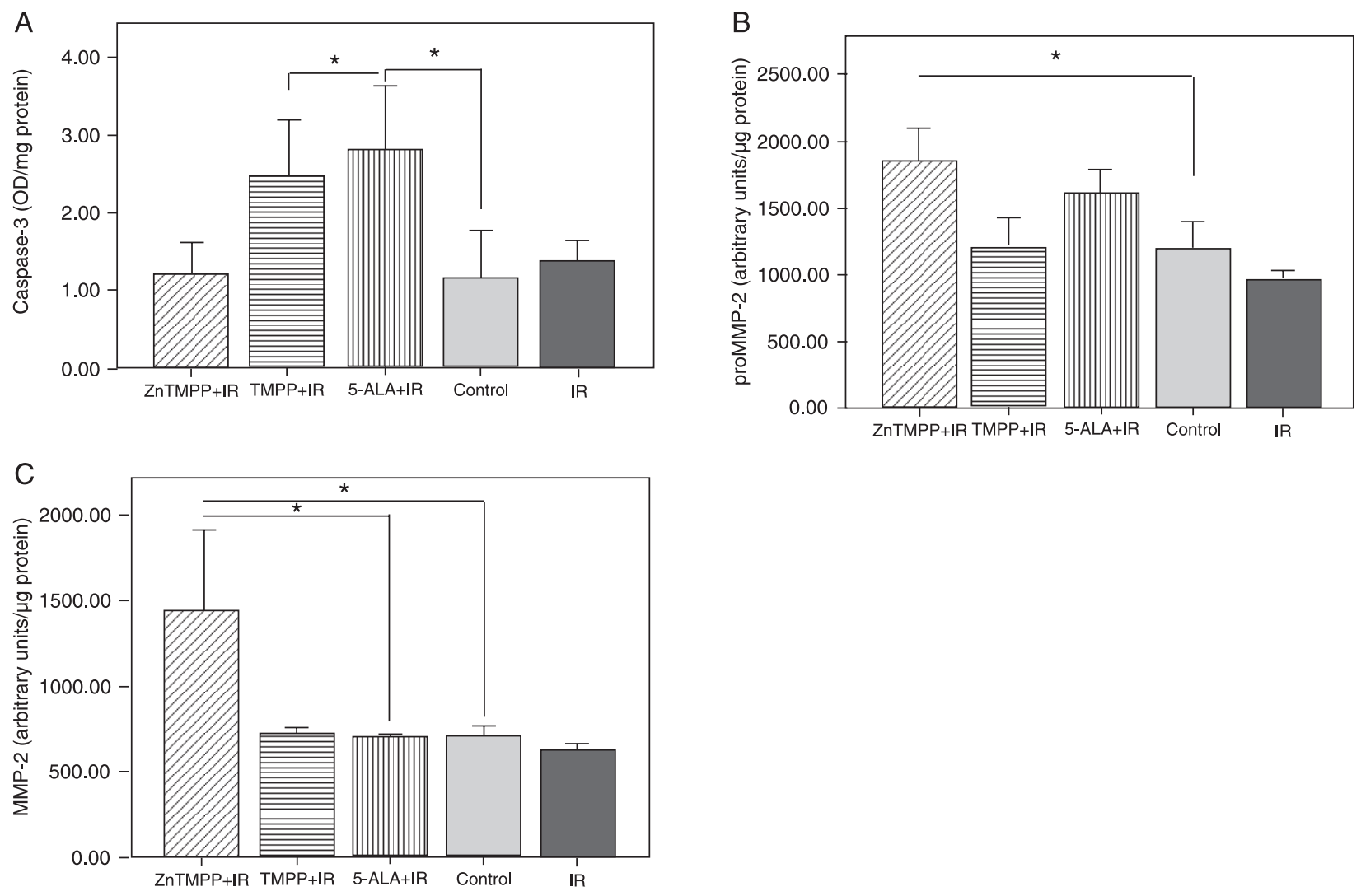

Figure 2. Activities of caspase-3 (A), proMMP-2 (B) and MMP-2 (C) in tumor tissue $24 \mathrm{~h}$ after photodynamic therapy with 5-ALA, TMPP and ZnTMPP. The results were compared with those of control and irradiated (IR) groups. Data are reported as means \pm SD of three independent experiments. MPP-2 = metalloprotease-2; proMMP-2 = pro-metalloprotease-2; 5-ALA = 5-aminolevulinic acid; TMPP = 5,10,15,20-tetrakis (4-methoxyphenyl)-porphyrin; ZnTMPP = TMPP zinc compound. Statistical analysis was done by the Mann-Whitney U-test and the Kruskal-Wallis test. $A,{ }^{*} \mathrm{P}<0.05 ; B,{ }^{*} \mathrm{P}<0.05 ; C,{ }^{*} \mathrm{P}<0.05$. 


\section{Discussion}

The purpose of oncologic PDT is to induce selective tumor eradication with minimal damage to adjacent normal tissues and without side effects in the patients. Physicochemical properties of a series of TMPP and results in vitro, on Hep-2 human larynx carcinoma cell line, have shown that these synthetic compounds could be used as efficient PS (27).

In the present study, we investigated in vivo the mechanisms involved in ZnTMPP and TMPP PDT effects compared to 5-ALA on Walker carcinosarcoma. Therefore, lipid peroxidation and antioxidant levels, apoptotic events and tumor cytokines were investigated in correlation with the histopathological findings in the tumor.

MDA is a common marker used to evaluate lipid peroxidation in tissues and its increased levels in tumors after PDT suggest that a type I mechanism may occur. Our experiments revealed that the tumor levels of MDA in ZnTMPP or TMPP PDT were remarkably high compared

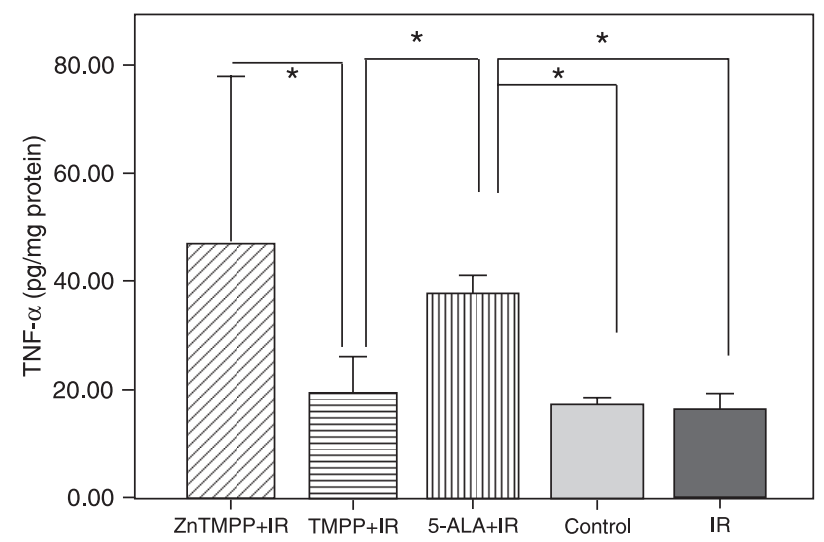

Figure 3. TNF- $\alpha$ level in tumor homogenates after photodynamic therapy applied to control, irradiated (IR), 5-ALA+IR, TMPP+IR and ZnTMPP+IR groups. TNF- $\alpha=$ tumor necrosis factor alpha; 5-ALA $=5$-aminolevulinic acid; TMPP $=5,10,15,20$-tetrakis $(4-$ methoxyphenyl)-porphyrin; ZnTMPP = TMPP zinc compound. Statistical analysis was done by the Mann-Whitney U-test and by the Kruskal-Wallis test. ${ }^{*} \mathrm{P}<0.05$.

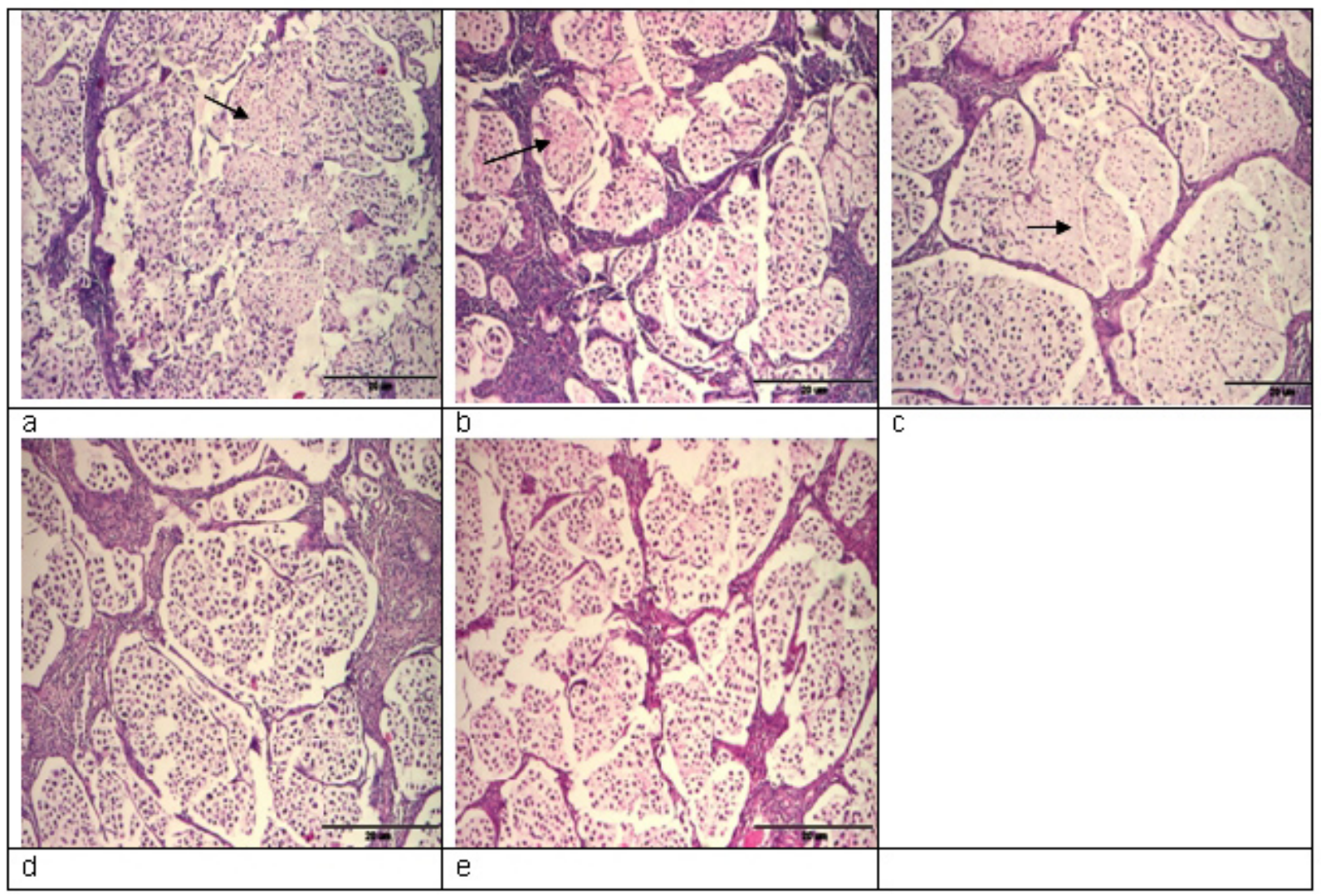

Figure 4. Histological aspect of tumors stained with hematoxylin and eosin. The effect of photodynamic therapy (PDT) was determined by evaluating the percentage of necrotic cells within the total number of cells under 400X magnification in a microscopic field of 10 randomly selected areas in each tumor sample (scale bar $=20 \mu \mathrm{m}$ ). At $24 \mathrm{~h}$ after PDT, amorphous cells with pyknotic or absent nuclei were observed, without clear intercellular limits. The magnification of the histological images was 40X. $a, \mathrm{ZnTMPP}+\mathrm{IR} ; b$, TMPP+IR; $c$, 5-ALA+IR; $d$, control group; e, IR group. TMPP = 5,10,15,20-tetrakis(4-methoxyphenyl)-porphyrin; ZnTMPP = TMPP zinc compound; 5-ALA = 5-aminolevulinic acid; IR = irradiation. 
to the control or IR groups, indicating that ROS may play an important role in photodynamic-induced cell damage. Moreover, in another study, the cytotoxic effect of TMPP PDT in vitro was correlated with singlet oxygen production (10) suggesting that this PS acts via a type II mechanism of reaction. Previous results from our laboratory have also shown that PDT with TMPP and ZnTMPP determined an increased level of thiobarbituric reactive substances (TBARS) as a measure of lipid peroxidation in tumor tissue as well as in blood plasma at $24 \mathrm{~h}$ after the treatment (28).

Reduced glutathione (GSH) defends the cells against oxidative damage by reacting with free radicals and peroxides (29). The glutathione levels in tumors increase significantly in ZnTMPP and TMPP PDT compared to 5-ALAPDT. We attributed the increase in GSH levels to the accumulation of lipid peroxides in cells. Other studies have shown that PDT, via NF-kB, induced the up-regulation of $\mathrm{Y}$-glutamylcysteine synthetase expression in response to oxidative stress-induced GSH depletion (30). Furthermore, discrepancies have been noted concerning the relationship that exists between antioxidant levels and tumor damage, as GSH levels have been reported to be increased, decreased or unaltered following PDT (31). Additionally, it has been shown that the activation of apoptosis-executing caspases actually requires sustained glutathione levels as these proteases possess an essential cysteine thiol in the active site (29). The direct correlation between the activity of caspase-3 and glutathione levels in the group treated with 5-ALA PDT $(P<0.05)$ shown in our study also supports this assumption.

Due to the very important role of caspases in the apoptotic pathway, the activity of their effectors was investigated. Caspase- 3 is counted among the effectors of caspases, which lead to apoptotic cell death. TMPP PDT increased the level of caspase-3 (1.66 times compared to the control group) but the values were lower than those obtained with 5-ALA (2.31 times compared to the control group) and higher than those obtained using ZnTMPP (1.14 times compared to the control group). ZnTMPP PDT had a small effect on apoptosis although the lipid peroxidation index was increased. Massive production of ROS in tumors exposed to ZnTMPP PDT may explain this observation. The $\mathrm{SH}$ groups of caspases are essential for their catalytic activity. Due to exposure to free radicals these $\mathrm{SH}$ groups may have been inactivated.

Beside the important role of mitochondria in the apoptotic process, activation of death receptors like Fas, TNF-R1 and TRAIL-R1/2 can also induce apoptosis (1). Death receptormediated apoptosis of tumor cells could be induced by autocrine production of either Fas ligand or TNF- $\alpha$ by the tumor or by the release of these factors from macrophages. ZnTMPP PDT led to increased quantities of TNF- $\alpha$ in tumor (2.51 times compared with the control group) compared to the group treated with TMPP PDT (1.14 times compared to the control group).
MMPs are responsible for the degradation of extracellular matrix proteins and are involved in tumor angiogenesis, growth, invasion, and metastatic potential (8). Evidence exists that MMP-2 and MMP-9 are involved in the involution and regression of the vessels in the later stages of angiogenesis (32).

In solid tumors, MMPs are often expressed by stromal cells and macrophages rather than by tumor cells. Increased MMP activities have been reported to occur after PDT $(33,34)$. Two members of the MMP family, the gelatinases MMP-2 and MMP-9, were investigated by zymography. Tumors treated with TMPP, ZnTMPP PDT or 5-ALA PDT showed only MMP-2 activity. In our experimental model, gelatin zymography applied to tumor homogenates revealed the induction of an enzymatically active form of MMP-2 after ZnTMPP and 5-ALA PDT. It is well known that MMPs are synthesized in a latent form and are transformed to biologically active proteases under the influence of some cytokines, growth factors, oncogenes, or ROS (9). It was shown that the production of ROS induces the activation of proMMP-2 (35). There was a significant correlation $(P<0.01)$ between the levels of proMMP-2 and tumor MDA in the group treated with 5-ALA PDT. The tumor sections stained with HE and examined under the light microscope $24 \mathrm{~h}$ after TMPP PDT and 5-ALAPDT showed a significantly higher percentage of necrotic cells $(P<0.02)$ compared to the values obtained after ZnTMPP+IR or to the control group.

In vivo studies of meso-tetraphenylporphyrin derivatives show that replacement of the methyl groups by methoxy substituents produces an increase in tumor/muscle and tumor/ skin ratios (36). A similar tendency was also observed for meso-tetraphenylporphyrin dimer derivatives (37). Recently, a novel meso-2,4,6-trimethoxyphenylporphyrin covalently linked to a trifluoromethylphenyl derivative was evaluated as a photosensitizer (38). An attractive photobiological feature is its ability to inactivate cultured tumor cells with high efficiency by apoptotic or necrotic modes, depending on the light dose.

The present results demonstrated that ZnTMPP and TMPP induced the death of tumor cells and, as a result, the destruction of the tumor, a process in which several mechanisms were involved: ROS generation, the release of TNF- $\alpha$, and the activation of caspase- 3 and MMP-2.

In conclusion, using this experimental model we demonstrated that PDT with ZnTMPP and TMPP had the capacity to generate ROS with cytotoxic effects on cell biomolecules. Irradiation with red light after PS administration resulted in the generation of lipid peroxides, which led to the activation of caspases and, finally, to the death of tumor cells. An important role in the triggering of cell death was played by the release of TNF- $\alpha$ in tumor cells. The complexing of TMPP with $\mathrm{Zn}$ determined a superior photodynamic effect and increased levels of MDA, GSH, and TNF- $\alpha$. The tested porphyrins were able to activate proMMP-2 to the mature state of the enzyme, thus promoting the proteolysis of 
the extracellular matrix. Our data indicate that PDT with TMPP and ZnTMPP has promising beneficial effects for cancer treatment. Further studies aiming to elucidate the efficacy of these porphyrins in PDT are in progress in our laboratory.

\section{References}

1. Nowis D, Makowski M, Stoklosa T, Legat M, Issat T, Golab J. Direct tumor damage mechanisms of photodynamic therapy. Acta Biochim Pol 2005; 52: 339-352.

2. Dougherty TJ, Gomer CJ, Henderson BW, Jori G, Kessel D, Korbelik M, et al. Photodynamic therapy. J Natl Cancer Inst 1998; 90: 889-905.

3. Almeida RD, Manadas BJ, Carvalho AP, Duarte CB. Intracellular signaling mechanisms in photodynamic therapy. Biochim Biophys Acta 2004; 1704: 59-86.

4. Dellinger M. Apoptosis or necrosis following Photofrin photosensitization: influence of the incubation protocol. Photochem Photobiol 1996; 64: 182-187.

5. Lam M, Oleinick NL, Nieminen AL. Photodynamic therapyinduced apoptosis in epidermoid carcinoma cells. Reactive oxygen species and mitochondrial inner membrane permeabilization. J Biol Chem 2001; 276: 47379-47386.

6. Oleinick NL, Morris RL, Belichenko I. The role of apoptosis in response to photodynamic therapy: what, where, why, and how. Photochem Photobiol Sci 2002; 1: 1-21.

7. Pazos MC, Nader HB. Effect of photodynamic therapy on the extracellular matrix and associated components. Braz $J$ Med Biol Res 2007; 40: 1025-1035.

8. Curran S, Murray GI. Matrix metalloproteinases: molecular aspects of their roles in tumour invasion and metastasis. Eur J Cancer 2000; 36: 1621-1630.

9. Ferrario A, Chantrain CF, von Tiehl K, Buckley S, Rucker N, Shalinsky DR, et al. The matrix metalloproteinase inhibitor prinomastat enhances photodynamic therapy responsiveness in a mouse tumor model. Cancer Res 2004; 64: 23282332.

10. Milanesio ME, Alvarez MG, Yslas EI, Borsarelli CD, Silber JJ, Rivarola $\mathrm{V}$, et al. Photodynamic studies of metallo 5,10,15,20-tetrakis(4-methoxyphenyl) porphyrin: photochemical characterization and biological consequences in a human carcinoma cell line. Photochem Photobiol 2001; 74 : $14-21$.

11. Alvarez MG, Yslas El, Rivarola V, Mori G, La Penna M, Silber $\mathrm{JJ}$, et al. Photodynamic effect of 5,10,15,20-tetrakis(4-methoxyphenyl) porphirine (TMP) on Hep-2 cell lines. Molecules 2000; 5: 379-380.

12. Adler AD, Longo FR, Goldmacher J, Assour J, Korsakoff L. A simplified synthesis for meso-tetraphenylporphine. J Org Chem 1967; 32: 476-487.

13. Ion RM. Spectrophotometric study of the photodegradation reaction of the tetra-aryl-porphyrins. The meso-substituent effect. Rev Chim 1993; 44: 431-435.

14. Ion RM. Spectrophotometric study of the photodegradation reaction of the tetra-aryl-porphyrins. The hydroperoxide effect. Rev Chim 1995; 46: 134-137.

15. Ion RM, Mandravel C. The photodegradation reaction of some porphyrins. South Braz J Chem Soc 1997; 5: 111-

\section{Acknowledgments}

Research supported by the Ministry of Education, Research and Youth by CEEX Program (\#102/2006).

129.

16. Ion RM, Grigorescu M. The synthesis computation of tetraarylporphyrins. Rev Chim 1997; 48: 324-328.

17. Ion RM, Stirbet A, Mandravel C. The analysis of the porphyrins purity. Rev Chim 2010; 49: 121-123.

18. Ion RM, Badescu V, Garbalau N, Palii S. Spectral considerations of TAPP photoreactivity. Anal Univ Buc 1999; VIII: 35-43.

19. Ion RM, Scarlat F. Metode neconventionale de sinteza a porfirinelor. Rev Chim 2004; 55: 900-904.

20. Anonymous. Guide for the Care and Use of Laboratory Animals Institute of Laboratory Animal Research, Commission on Life Sciences, National Research Council. Washington: National Academy Press; 1996.

21. Conti M, Morand PC, Levillain P, Lemonnier A. Improved fluorometric determination of malonaldehyde. Clin Chem 1991; 37: 1273-1275.

22. Bradford MM. A rapid and sensitive method for the quantitation of microgram quantities of protein utilizing the principle of protein-dye binding. Anal Biochem 1976; 72: 248-254.

23. Hu ML. Measurement of protein thiol groups and glutathione in plasma. Methods Enzymol 1994; 233: 380-385.

24. Granelli-Piperno A, Reich E. A study of proteases and protease-inhibitor complexes in biological fluids. J Exp Med 1978; 148: 223-234.

25. Peterson GL. A simplification of the protein assay method of Lowry et al. which is more generally applicable. Anal Biochem 1977; 83: 346-356.

26. Weibel ER, Gehr P, Cruz-Orive LM, Muller AE, Mwangi DK, Haussener $V$. Design of the mammalian respiratory system. IV Morphometric estimation of pulmonary diffusing capacity; critical evaluation of new sampling method. Respir Physiol 1981; 44: 39-59.

27. La Penna, Alvarez MG, Yslas El, Rivarola V, Durantini EN. Photodynamic activity of 5,10,15,20-tetrakis(4-methoxyphenyl)porphyrin on the Hep-2 human carcinoma cell line: effect of light dose and wavelength range. Bioorg Chem 2001; 29 : 130-139.

28. Daicoviciu D, Filip A, Ion RM, Clichici S, Decea N, Muresan A. Oxidative photodamages induced by photodynamic therapy with methoxyphenyl porphyrin derivatives in tumor bearing rats. Folia Praga 2010 (in press).

29. Calzavara-Pinton PG, Venturini M, Sala R. Photodynamic therapy: update 2006. Part 1: Photochemistry and photobiology. J Eur Acad Dermatol Venereol 2007; 21: 293-302.

30. Wu G, Fang YZ, Yang S, Lupton JR, Turner ND. Glutathione metabolism and its implications for health. J Nutr 2004; 134 : 489-492.

31. Lomaestro BM, Malone M. Glutathione in health and disease: pharmacotherapeutic issues. Ann Pharmacother 1995; 29: 1263-1273. 
32. Tatar O, Adam A, Shinoda K, Eckert T, Scharioth GB, Klein $M$, et al. Matrix metalloproteinases in human choroidal neovascular membranes excised following verteporfin photodynamic therapy. Br J Ophthalmol 2007; 91: 1183-1189.

33. Filip A, Clichici S, Muresan A, Daicoviciu D, Tatomir C, Login C, et al. Effects of PDT with 5-aminolevulinic acid and chitosan on Walker carcinosarcoma. Exp Oncol 2008; 30: 212-219.

34. Clichici S, Filip A, Daicoviciu D, Ion RM, Mocan T, Tatomir C, et al. The dynamics of reactive oxygen species in photodynamic therapy with tetra sulfophenyl-porphyrin. Acta Physiol Hung 2010; 97: 41-51.

35. Gomer CJ, Ferrario A, Luna M, Rucker N, Wong S. Photodynamic therapy: combined modality approaches targeting the tumor microenvironment. Lasers Surg Med 2006; 38: 516-521.

36. Reddi E, Segalla A, Jori G, Kerrigan PK, Liddell PA, Moore $A L$, et al. Carotenoporphyrins as selective photodiagnostic agents for tumours. Br J Cancer 1994; 69: 40-45.

37. Faustino MA, Neves MG, Cavaleiro JA, Neumann M, Brauer HD, Jori G. Meso-tetraphenylporphyrin dimer derivatives as potential photosensitizers in photodynamic therapy. Part 2. Photochem Photobiol 2000; 72: 217-225.

38. Milanesio ME, Moran FS, Yslas EI, Alvarez MG, Rivarola V, Durantini EN. Synthesis and biological evaluation of methoxyphenyl porphyrin derivatives as potential photodynamic agents. Bioorg Med Chem 2001; 9: 1943-1949. 